\title{
DILEMAS ÉTICOS VIVENCIADOS PELO ENFERMEIRO FRENTE A TOMADA DE DECISÃO NO PREIOPERATÓRIO
}

\author{
Gilza Bastos da silva ${ }^{1}$; Marluce Alves Nunes Oliveira ${ }^{2}$ \\ 1. Bolsista PEVIC, Graduando em Enfermagem, Universidade Estadual de Feira de Santana, \\ e-mail:gilzabastos54@gmail.com \\ 2. Orientador, Departamento de Saúde, Universidade Estadual de Feira de Santana, e-mail: milicialves@ yahoo.com.br
}

PALAVRAS-CHAVE: Centro Cirúrgico, Ética, Tomada de decisões.

\section{INTRODUÇÃO}

O dilema ético é uma situação que se coloca diante da dificuldade de escolher a solução ideal, diante de um raciocínio que parte de premissas contraditórias e mutuamente excludentes, em relação a uma determinada situação, ambas ingratas ou mesmo contrárias (GERMANO, 2013).

O CC é uma "unidade destinada ao desenvolvimento de atividades cirúrgicas, bem como a recuperação pós-anestésica e pós-operatória imediata" (OLIVEIRA; SANRA ROSA, 2014, p.17). Dessa forma no contexto do CC, o enfermeiro está exposto a situações que suscitam dilemas éticos que o leva a necessidade de tomar decisões. Para Oliveira (2012, p.104), a tomada de decisão envolve aspectos individuais e coletivos, havendo a necessidade de estabelecer uma meta, um objetivo ao qual se pretende chegar, a escolha de alternativa para alcançar o fim almejado.

A prática do enfermeiro que atua no $\mathrm{CC}$ esta pautada por uma gama de atividades desenvolvidas durante a assistência no pré-operatório, intraoperatório e pós-operatório, ou seja, cuida dos pacientes desde a admissão até a alta no pós-operatório imediato (OLIVEIRA, 2012), considerado como perioperatório.

O enfermeiro tem sua atuação embasada no Código de Ética dos Profissionais (CEPE), mas o processo de decisão pode estar baseado nas vivências do cotidiano. No CEPE, nos Princípios Fundamentais, assegura que "O profissional de enfermagem exerce suas atividades com competência para promoção do ser humano na sua integralidade, de acordo com os princípios da ética e da bioética". (CONSELHO REGIONAL DE ENFERMAGEM, 2013, p. 103).

A motivação para realizar esta pesquisa surgiu com a vivência prática no componente curricular Enfermagem na Saúde do Adulto e Idoso II, do Curso de Enfermagem da Universidade Estadual de Feira de Santana, na unidade do CC, onde foi possível observar que o enfermeiro vivencia dilemas éticos que o leva a tomada de decisão. A partir da inquietação surgiu a questão de investigação: Como o enfermeiro toma decisão diante os dilemas éticos vivenciado no perioperatório?.

Este estudo tem como objetivo geral conhecer os dilemas éticos vivenciados pelo enfermeiro na tomada de decisão no perioperatório e como objetivos específicos descrever os dilemas éticos vivenciados pelo enfermeiro na tomada de decisão no perioperatório, elaborar estratégias para subsidiar a tomada de decisão do enfermeiro no perioperatório frente aos dilemas éticos.

\section{METODOLOGIA}

A pesquisa qualitativa responde a questões particulares, por trabalhar com o universo dos significados dos motivos, das aspirações, das crenças, dos valores e das atitudes. Ela se ocupa, nas ciências sociais com um nível de realidade que não pode e não deve ser mensurado (MINAYO, 2007). 
Trata-se de um estudo qualitativo, exploratório - descritivo. Tendo como objeto de estudo dilemas éticos vivenciados pelo enfermeiro na tomada de decisão no perioperatório.

O estudo foi desenvolvido na unidade de CC de um hospital geral público de grande porte, localizado no município de Feira de Santana-BA-Brasil. Os participantes da pesquisa foram 04 profissionais da equipe de enfermagem que atuam no centro cirúrgico com mais de um ano e em atividade laboral, sendo considerada a saturação dos dados.

As informações foram coletadas nos meses de junho e julho de 2017 , por meio de entrevista semiestruturada, que continham as seguintes questões norteadoras: como compreende o dilema ético? Fale-me de um dilema ético vivenciado no perioperatório e Quais estratégias são utilizadas para tomar decisão frente aos dilemas éticos vivenciados no perioperatório.

Os dados empíricos foram analisados a partir do método de análise de conteúdo de Bardin (2011). A análise de conteúdo "compreende técnicas de pesquisa que permitem, de forma sistemática, a descrição das mensagens e das atitudes atreladas ao contexto da enunciação, bem como as inferências sobre os dados coletados" (CAVALCANTE; CALIXTO; PINHEIRO, 2014, p. 14).

Este projeto de pesquisa está inserido no projeto VIVÊNCIAS DE CONFLITOS E DILEMAS ÉTICOS NA PERCEPÇÃO DA EQUIPE ENFERMAGEM NO CENTRO CIRÚRGICO. O projeto foi submetido ao Comitê de Ética em Pesquisa da Universidade Estadual de Feira de Santana, sob CAAE n 28656214.9.0000.0053.

Durante o desenvolvimento da pesquisa foram considerados os aspectos éticos que envolvem pesquisas com seres humanos, estabelecidos pela Resolução n ${ }^{\circ}$ 466/2012, do Conselho Nacional de Saúde (CNS).

\section{ANÁLISE E DISCUSSÃO DOS RESULTADOS}

Dos 04 profissionais da equipe de enfermagem que participaram da pesquisa, 01 do sexo masculino e 03 do sexo feminino, 10 anos tem o enfermeiro com maior tempo de atuação no $\mathrm{CC}$ e a mais recentemente possui 01 ano. Em relação ao tempo de conclusão do curso de formação profissional, a mais antiga possui 11 anos de formação e o mais recente cinco anos e dois meses, quanto ao vínculo empregatício, todos entrevistados possuem outros vínculos.

A partir da análise foram construídas três categorias: "Compreensão de dilemas éticos pelo enfermeiro que atua no perioperatório", "Vivencias de dilemas éticos pelo enfermeiro no perioperatório" e "Estratégias que o enfermeiro utiliza para tomar decisão no perioperatório".

\section{CATEGORIA I - COMPREENSÃO DE DILEMAS ÉTICOS PELO ENFERMEIRO QUE ATUA NO PERIOPERATÓRIO}

Os depoimentos dos participantes do estudo mostraram que o dilema ético é entendido como uma situação onde há um conflito que precisa ser resolvido de acordo com CEPE. O dilema ético e percebido como um conflito que precisa de uma solução, e o dilema ético é uma situação conflituosa, onde se faz necessário tomar uma solução, que deve ser sempre a decisão correta. A tomada de decisões é essencial à natureza humana; deste modo, tem relação com as distintas noções de cultura, sendo um componente da atuação profissional de enfermagem, que está atrelada à prática (BALIZA et al; 2015). Os enfermeiros observam em sua prática a legislação da enfermagem para sanar o dilema de acordo com o que diz o CEPE. O enfermeiro, no exercício de sua profissão, deve atuar com competência, observando os princípios da ética e da bioética (CONSELHO FEDERAL DE ENFERMAGEM, 2013). 


\section{CATEGORIA II- DILEMAS ÉTICOS VIVENCIADOS PELO ENFERMEIRO NO PERIOPERATÓRIO}

Nesta categoria, os participantes mostram as suas experiências relacionadas com o dilema ético no perioperatório, envolvendo o relacionamento da equipe multiprofissional. Percebemos que existe dificuldade no relacionamento interpessoal entre a equipe multiprofissional, os relatos demonstram que há um conflito nas relações entre os membros da equipe cirúrgica, em especial a equipe médica, devido a disputa por horário e sala para realização de cirurgias, estando em jogo interesses pessoais. Concordamos com Bruinsma et al., (2017) quando coloca que os conflitos pertencem a realidade dos seres humanos, podem advir da diferença de valores e vaidades entre pessoas, equipe de trabalho e sociedades.

\section{CATEGORIA III - ESTRATÉGIAS QUE O ENFERMEIRO UTILIZA PARA TOMAR DECISÃO FRENTE A DILEMAS ÉTICOS NO PERIOPERATÓRIO}

O diálogo é o instrumento mais utilizado a fim de subsidiar a tomada de decisões. Comunicar e corresponsabilizar a equipe em determinadas situações de conflito, buscando sempre observar o código de ética para fundamentar a decisão tomada. Observamos que os enfermeiros tomam decisões em equipe, sendo consultada acerca da melhor alternativa para dá resolutividade ao dilema ético que emergiu. Sendo o diálogo fundamental para esse processo. A tomada de decisão utiliza elementos subjetivos que traspõem ao conhecimento técnico (SIMON, 1960). Nos relatos os enfermeiros revelam que utilizam o código de ética para tomar decisões, entretanto, existe deficiência no que diz respeito a ter conhecimento dos princípios da bioética. Nesse sentido, Oliveira e Santa Rosa (2014) salientam que a bioética se preocupa com o impacto das decisões na sociedade.

\section{CONSIDERAÇÕES FINAIS}

Esta investigação possibilitou conhecer os dilemas éticos vivenciados pelo enfermeiro na tomada de decisões no perioperatório, bem como as estratégias utilizadas para tomar decisões frente aos dilemas éticos vivenciado na prática no perioperatório.

Os participantes demonstraram compreender o significado de dilema ético, sendo uma situação em que existe o conflito e precisa de tomar uma decisão.

$\mathrm{O}$ estudo apontou que as vivências dos dilemas éticos estão relacionadas como o relacionamento entre a equipe multiprofissional.

As estratégias utilizadas pelos enfermeiros para tomar decisão diante do dilema ético são fundamentadas no diálogo e na legislação da enfermagem, a fim de agir eticamente, garantindo uma assistência de qualidade.

Os enfermeiros vivenciam dilemas éticos no perioperatório, sendo importante fortalecer o relacionamento interpessoal/comunicação entre os membros da equipe multiprofissional de forma a promover respeito no ambiente laboral, utilizando estratégias que valorizem o agir ético, minimizando os conflitos entre a equipe.

As dificuldades encontradas para realizar este estudo dizem respeito a rotina da equipe de enfermagem no CC que dificultou a realização das entrevistas.

A partir destes achados, outros estudos sobre esta temática devem ser realizados e divulgados, permitindo o conhecimento e reflexão a despeito os dilemas éticos vivenciados pelo enfermeiro na tomada de decisão no perioperatório e quais estratégias são utilizadas por eles para tomar decisões pautadas nos princípios éticos e legais da profissão. 


\section{REFERÊNCIAS}

BAHIA. Secretária da Saúde do Estado da Bahia. HGCA - Hospital Geral Clériston Andrade: histórico. Feira de Santana, 2016. Disponível em:

<http://www.saude.ba.gov.br/hgca/index.php?option=com_content\&view=article\&id=308\&It emid=188>. Acesso em: 28 fev 2016.

BARDIN, L. Análise de conteúdo. São Paulo: Edições 70, 2011.

BRASIL. Ministério da Saúde. Resolução CNS 466/12. Conselho Nacional de Saúde.

Comissão Nacional de Ética e Pesquisa com Seres Humanos. 2012. Disponível em: < http://conselho.saude.gov.br/resolucoes/2012/Reso466.pdf >Acesso em: 13 de jul. 2012.

BALIZA; Michelle Freire, et al. Fatores que influenciam os enfermeiros de unidades de terapia intensiva nas decisões de final de vida. Revista Esc de Enfermagem USP, São Paulo, 2015. Disponível em: <www.scielo.br/pdf/reeusp/v49n4/pt_0080-6234-reeusp-49-040572.pdf>. Acesso em: 13 de dez de 2016.

BRUINSMA, Jamile Lais et al., Conflitos entre idosas institucionalizadas: dificuldades vivenciadas pelos profissionais de enfermagem. Escola Anna Nery revista de enfermagem, Rio de Janeiro. 21(1): e20170020, 2017.

CAVALCANTE, R. B.; CALIXTO, P.; PINHEIRO, M. M. K. 2014. Análise de conteúdo: considerações gerais, relações com a pergunta de pesquisa, possibilidades e limitações do método. Inf. \& Soc.: João Pessoa, v.24, n.1, p. 13-18, jan./abr.

CONSELHO FEDERAL DE ENFERMAGEM (COFEN). Resolução COFEN n 311, de 08 de fevereiro de 2007. Aprova a reformulação do Código de Ética dos Profissionais de Enfermagem. In: CONSELHO REGIONAL DE ENFERMAGEM DA BAHIA (CORENBA). Legislação básica para o exercício da enfermagem. Salvador: COREN-BA, 2013.

GERMANO, Raimunda Medeiros. A pesquisa e os dilemas éticos do trabalho da enfermagem. Rev Brasileira de Enfermagem. Rio Grande do Norte, Junho de 2013. Disponível em: < http://www.scielo.br/pdf/reben/v66nspe/v66nspea10.pdf>. Acesso em: 26 de jan de 2016.

MINAYO, Maria Cecília de Souza; DESLANDES, Suely Ferreira. Pesquisa social teoria, método e criatividade. 26. ed. Petrópolis: Vozes, 2007. 108 p.

OLIVEIRA, Marluce Alves Nunes; SANTA ROSA, Darci de Oliveira. Método de Análise de Problemas Morais aplicado à prática da Enfermagem. Feira de Santana: UEFS Editora, 2014. 184p.

OLIVEIRA, Marluce Alves Nunes. Gerenciamento de novas tecnologias em centro cirúrgico pelas enfermeiras nos hospitais de Feira de Santana-Ba. Dissertação [ Mestrado]. Universidade federal de Santana Catarina, Florianópolis, 2012.

SIMON, Herbert Alexander. The new science of management decision. New York, 1960. 